\title{
UNIÓN EUROPEA, CRISIS ECONÓMICA Y ELECCIONES AL PARLAMENTO EUROPEO 2014
}

\author{
Montserrat Abad Castelos \\ Universidad Carlos III de Madrid \\ Juan San Segundo Manuel ${ }^{1}$ \\ Universidad Complutense de Madrid
}

http://dx.doi.org/10.5209/rev_NOMA.2014.v43.n3.49281

Resumen.- En un contexto en que los países de la zona euro todavía se ven afectados negativamente por la crisis económica se celebran elecciones al Parlamento Europeo. Este comentario expone la evolución experimentada por el Parlamento de la UE, incidiendo sobre todo en su importancia actual, a través de muestras concretas de su posible influencia. Pero ante todo se persigue mostrar por qué las elecciones de 2014 son las más relevantes hasta la fecha y cómo los ciudadanos europeos pueden influir a través de ellas en su futuro.

Palabras clave.- Unión Europea (UE), Parlamento Europeo (PE), elecciones.

Abstract.- In a context in which the countries of the eurozone are still adversely affected by the economic crisis, European Parliament elections are held. This article presents the evolution experienced by the EU Parliament, focusing especially on its present importance, through tangible evidences of its possible influence. But above all it aims to show why the 2014 elections are the most important to date and how European citizens can influence through them in their future.

Key Words.- European Union (EU); European Parliament (EP); elections.

\footnotetext{
${ }^{1}$ Montserrat Abad Castelos es profesora titular de Derecho internacional público en la Universidad Carlos III de Madrid. Juan San Segundo Manuel es asesor técnico de la Asamblea de Madrid y profesor asociado de Derecho Constitucional en la Universidad Complutense de Madrid.
} 


\section{Introducción: el carácter hoy imprescindible de la Unión Europea (UE), como premisa}

El 2014 es año de cita electoral de los ciudadanos de Europa con el Parlamento Europeo, prevista para el 25 de mayo. Aunque el presente artículo se ha enviado a la imprenta antes de dicha fecha, y por tanto sin conocer sus resultados, el objetivo principal de este comentario es, en realidad, el examen de otras cuestiones relevantes relativas a estas elecciones, que poco pueden verse afectadas por detalles concretos de su realización. Por ello, debemos comenzar recordando que las elecciones en general, constituyen el acto de participación política por excelencia en nuestro modelo de democracia representativa. De hecho, entre las principales atribuciones que todo Parlamento, que merezca tal nombre, ostenta como principales, se encuentran precisamente la función representativa y la del ejercicio del control democrático.

A la luz de lo anterior, y antes de examinar más detenidamente sus implicaciones, es preciso ser conscientes de la trascendencia de la UE, la cual, a pesar de las tormentas de diverso tipo que sacuden a la sociedad actual, tiene un papel consolidado que, además de sus competencias crecientes, ya cubre a 28 Estados de Europa, desde que se hizo efectivo el ingreso de Croacia, el 1 de julio de 2013. Si bien los Estados europeos han estado tradicionalmente en una posición aventajada, cabe observar como Europa perdió su papel de faro en múltiples facetas ya durante el siglo pasado. Es obvio que, en líneas generales, ha dejado de estar en vanguardia, y hoy en día se abren nuevos centros de gravedad mundiales fuera del Mediterráneo, en otras zonas que se han ido convirtiendo en áreas estratégicamente fundamentales: primero, el Atlántico, después, el Pacífico, y, aun en el presente, el Índico ${ }^{2}$. Parece evidente asimismo que la posible recuperación de un papel más relevante para los Estados europeos en todos los ámbitos importantes, como el económico, el político o el de la seguridad, en el marco de la compleja sociedad globalizada de nuestros días, sólo puede pasar por la UE. Por ello, con esta asunción partimos, como premisa, no sólo de la importancia de la UE, sino de su necesidad.

\footnotetext{
${ }^{2}$ Sobre este ascenso no sólo de China, sino en general de Asia, puede verse un reciente documento del Instituto Elcano: M. Esteban, "El ascenso de China y Asia: ¿qué nos dice el Índice Elcano de Presencia Global?", ARI, 14/2014 - 6/3/2014.
} 


\section{Críticas a la UE en el marco de la crisis actual de la representación política}

A pesar de lo imprescindible que es la UE para avanzar, ésta se ve envuelta en críticas y objeciones de distinto tipo y alcance en el estadio actual, que, con independencia ahora de sus fuentes, pueden ser calificadas según los casos como euroescépticas, eurófobas, o incluso como xenófobas y populistas ${ }^{3}$. No se le oculta a nadie que, si bien las razones de fondo provenientes de los sectores más radicales de la derecha y de la izquierda son en gran medida diferentes, sin embargo, "en sendos ámbitos el rechazo del establishment comunitario suele ser política y electoralmente rentable"4. Estas denuncias también afectan a la institución representativa por antonomasia, es decir, al Parlamento, y a sus miembros. En este sentido, podemos citar un dato preocupante, según el Eurobarómetro publicado en la primavera de 2013, los europeos parecen estar desencantados con la UE, al cifrarse el desencanto en torno al 55\% de la media europea ${ }^{5}$. Por consiguiente, trataremos de conocer y afrontar aquí sintéticamente ciertos aspectos relevantes conectados con tales críticas.

Primeramente, debemos partir de la existencia, en general, de una crisis de las instituciones representativas, la cual se ha ido extendiendo en mayor o menor medida al resto de las instituciones. Crisis que no es nueva, puesto que ya comenzaría a percibirse en numerosos países a partir de los años $70^{6}$. No obstante, la crisis económica actual, que ha azotado con especial virulencia a ciertos países de la zona euro, entre ellos a Grecia, Irlanda, Portugal y España, ha acentuado significativamente, además, el citado distanciamiento ciudadano. Esta situación política y sus motivos no pueden pasarse por alto, ya que sólo teniéndolos en cuenta y eliminando sus causas, podrán superarse ciertos planteamientos destructivos que,

\footnotetext{
${ }^{3}$ Para un examen de las características de ciertos grupos extremistas, que se detiene una década atrás, véase J.L. Rodríguez Jiménez, La extrema derecha europea, Alianza Editorial, Madrid 2004. También del mismo autor, "Como rentabilizar los sentimientos xenófobos", Crítica, Núm. 925, 2005, págs. 36-40.

${ }^{4}$ C. Rodríguez-Aguilera de Prat, "Euroescepticismo y partidos radicales: ¿todos iguales?", Ciudadanía europea y Democracia. La reforma del acta electoral y de los partidos políticos europeos, G. Garzón Clariana (Ed.), Marcial Pons, Madrid, 2012, pp. 143-.156; p. 143. Este mismo autor añade que "en todo caso, el mayor grado de contestación se da en las derechas radicales -las que más se han beneficiado del impasse de la UE-, aunque las izquierdas radicales tienen, a su vez, una incidencia media no tan menor como suele suponerse en comparación con aquéllas"; ibídem.

${ }^{5}$ European Commission - IP/13/725 23/07/2013 (disponible en http://europa.eu/rapid/pressrelease_IP-13-725_es.htm). En el caso de España, el nivel de desencanto incluso sube bastante por encima, concretamente hasta el $72 \%$; ibid.

${ }^{6}$ Ciertos rasgos y efectos de esa crisis eran analizados por el sociólogo alemán U. Beck en su libro sobre La Sociedad del riesgo (Hacia una nueva modernidad) (Traducción de J. Navarro,
} 
además, se retroalimentan. Entre las razones económicas que explican la intensidad de la crisis de la representación actual se encuentran los altos niveles de desempleo, el paro juvenil, la profundización de las desigualdades, la supresión y reducción de servicios sociales a cargo de instituciones públicas, etc., las cuales se viven en ciertos países (o en determinados sectores de población), incluso a pesar de que los indicadores macroeconómicos de los Estados se vayan recuperando. En definitiva, tal y como ha ocurrido en otras etapas históricas, con circunstancias económicas adversas se acentúa lo local, lo nacional, e incluso la xenofobia y el racismo, frente a valores solidarios, europeos o internacionales.

Pero no podemos olvidar, en cualquier caso, que esa desafección ciudadana con respecto a las instituciones ya existía, aunque fuera en menor grado, antes de las crisis financiera y económica. Tanto es así, que en el marco de la UE tal vez el factor que posiblemente ha alimentado las mayores críticas tiene que ver con su denominado déficit democrático ${ }^{7}$, expresión tan traída y llevada, especialmente años atrás ${ }^{8}$.

\section{El papel del Parlamento Europeo: avances democráticos en la UE}

Sin entrar aquí en los últimos avances habidos en lo que respecta a la democracia participativa a través de la nueva iniciativa popular incluida en el Tratado de Lisboa $^{9}$, ha de señalarse que la regulación jurídica del PE ha sido uno de los aspectos conectados con los elementos democráticos de la Unión en los que se ha ido avanzando más con las sucesivas reformas de los tratados constitutivos ${ }^{10}$. De hecho,

D. Jiménez y M.R. Borrás), 1a Edición en castellano (publicado originalmente en alemán, en 1986), Paidós, Barcelona, 1998; véanse en particular las pp. 248 y ss.

7 Véase J.I. Torreblanca, 'Unión Europea: del 'superávit democrático' al 'déficit democrático', en J. Estefanía, Informe sobre la Democracia en España 2013, Fundación Alternativas, Madrid.

${ }^{8}$ Véase A. Moravcsik, "In Defence of the Democratic Deficit: Reassessing Legitimacy in the European Union”, Journal of Common Market Studies, Vol. 40, 2002, pp. 603-624.

${ }^{9}$ Sobre ello, puede verse European Citizen Action Service, "European Citizens' Initiatives - A first assessment", Background Discussion Document No. 1 for the Conference "Building the EU Citizen pillar", November 2012 (European Economic and Social Committee), Brussels, Belgium (http://www.ecas-citizens.eu/content/view/468/); European Citizen Action Service, Bringing transnational participatory democracy to life: tips for the would-be organisers of an ECl, July. ECAS publication, Brussels, Belgium, 2011; B. Kauffmann, "European Citizens' Initiative Pocket Guide", Initiative and Referendum Institute and the Green Foundation, March 2012, Belgium.

${ }^{10}$ Sobre la evolución de su régimen jurídico, examinando en particular el derecho de sufragio y el sistema y procedimiento electoral, véase M. Martín de Hijas Merino, "Sistema electoral al 
como señala Î́nigo Méndez de Vigo", "de las tres instituciones sobre las que descansa el gobierno de la Unión" es "la que más ha evolucionado y la que más poder ha ganado a lo largo del tiempo"12. Así, se ha reconocido la elección directa de sus miembros desde 1979, se han ido potenciado progresivamente sus funciones, hasta llegar a la situación actual, en que su condición democrática y de control aparece bien fortalecida, por diversas causas ${ }^{13}$. En palabras de Martin Schultz, "el Tratado de Lisboa ha significado un claro avance de la democracia parlamentaria en la Unión Europea: en él, el funcionamiento de la Unión encuentra su fundamento en la democracia representativa, el Parlamento Europeo aparece como la cámara que representa directamente a los ciudadanos europeos, y el Presidente de la Comisión Europea ha de ser elegido teniendo en cuenta el resultado de las elecciones europeas" ${ }^{\prime 14}$.

Para empezar, destacamos el hecho de que el PE ha sido dotado con mayores atribuciones, dentro de las cuales se encuentra el incremento de la función legislativa, pues pasa a estar prácticamente en pie de igualdad con el Consejo -el colegislador con quien comparte esta función-. A través del procedimiento legislativo ordinario ambas instituciones codeciden para la adopción de la mayoría de las normas de la Unión.

A su vez, debe indicarse que una de las funciones que se potencian en la última reforma -la del Tratado de Lisboa-, entrada en vigor en diciembre de 2009, es la función presupuestaria. Ésta se lleva también a cabo por el PE con el Consejo en una situación de paridad. Tanto es así, que al finalizar el procedimiento presupuestario el Parlamento puede aprobar o rechazarlo en su totalidad. Debe insistirse ahora en la importancia que tiene el presupuesto. No sólo no es baladí, sino que tiene una significación política de primer orden. A este respecto cabe recordar que precisamente el embrión del parlamentarismo aparece con el presupuesto, ya muy avanzada la

Parlamento Europeo", Estado Democrático y Elecciones Libres: Cuestiones fundamentales de Derecho electoral, Thomson Reuters, 2010, pp. 321-361.

${ }_{11}^{11}$ Antiguo europarlamentario y actual Secretario de Estado para la UE de España.

12 I. Méndez de Vigo, "Prólogo", Ciudadanía europea y Democracia. La reforma del acta electoral y de los partidos políticos europeos, G. Garzón Clariana (Ed.), Marcial Pons, Madrid, 2012, pp. 19-22; p. 19.

${ }^{13}$ Sobre la evolución experimentada por el PE y sus rasgos y competencias actuales, pueden verse, entre otros, D. Liñán Nogueras y A. Mangas Martín, Instituciones y Derecho de la UE, Tecnos, Madrid, 2012; G.C. Rodríguez, Iglesias y M. López Escudero, "Estructura institucional de la Unión Europea", Las Organizaciones Internacionales, M. Díez de Velasco (16ª edición, coordinada por J.M. Sobrino Heredia), Tecnos, Madrid, 2010, pp. 617 y ss.

${ }_{14}$ M. Schulz, "Introducción", Ciudadanía europea y Democracia. La reforma del acta electoral y de los partidos políticos europeos, G. Garzón Clariana (Ed.), Marcial Pons, Madrid, 2012, pp. 23-27; p. 23. 
Edad Media. El presupuesto es, en puridad, la expresión de la política en cifras. Por tanto, refleja exactamente en el caso de la UE la realidad de su política, su verdadero orden de valores y prioridades, o, dicho de otra forma, en qué se gasta, con qué alcance y cómo se reparten y distribuyen las distintas partidas.

Otra de las funciones potenciadas (también típica de los parlamentos) es la de participar en los nombramientos de los cargos más importantes de la UE. Será con estas elecciones cuando se realice por primera vez la participación decisiva del PE en la elección del Presidente de la Comisión, lo cual sin duda le da una relevancia especial a estas elecciones.

Por último, el Parlamento también ha progresado de forma notable en lo atinente a sus funciones de control político, lo cual se conecta en especial con respecto a la Comisión, ya que puede solicitar su comparecencia, y, sobre todo, dispone del relevante poder de la posible censura frente al conjunto de sus miembros. Junto a esta figura ${ }^{15}$, tan característica del sistema parlamentario, también se ha incrementado el control a las dos Instituciones intergubernamentales que encarnan los intereses de los Estados, es decir, el Consejo y el Consejo Europeo. De hecho, está prevista la comparecencia de ambas instituciones. Con respecto al Consejo, concretamente el PE lo supervisa al poder plantearle cuestiones escritas u orales y, asimismo, puede incluso constituir comisiones de investigación.

Es claro, en definitiva, el avance progresivo del PE, aproximándose a las atribuciones de un Parlamento nacional, pese a que la participación ciudadana en las elecciones europeas ha descendido de manera constante desde la primera cita electoral que tuvo lugar en $1979^{16}$. En todo caso, hay que congratularse por ese

\footnotetext{
${ }^{15}$ Ya en varias ocasiones el PE ha mostrado su capacidad de influencia en relación con la Comisión. En 2004, el PE obligó a Italia a cambiar su candidatura inicial de Rocco Buttiglioni para formar parte de la Comisión Europea. Aunque J.M. Durao Barroso ya le había asignado la vicepresidencia y la cartera de Justicia, Libertad y Seguridad, los parlamentarios consideraron que Buttiglione no era apto para dicho puesto al advertir su posición extremista tras escuchar sus opiniones sobre la homosexualidad y el matrimonio durante su examen ante la Eurocámara. Asimismo, en igual año Kovács fue también elegido como miembro húngaro de la Comisión. Si bien inicialmente iba a ocupar la Comisaría de Energía, fue rechazado para tal puesto por el PE (no obstante, la negativa del gobierno húngaro de proponer a un nuevo comisario obligó a que el presidente lo mantuviera en la Comisión, aunque en otro cargo). En 2009, Rumiana Jeleva, propuesta por el Gobierno de Bulgaria para la Comisaría de Ayuda Humanitaria se vio obligada a retirarse debido a la acusación de falta de suficiente preparación para el cargo y falta de transparencia en su declaración de intereses.

${ }^{16}$ Según indica S. Piedrafita, entre las razones alegadas por los ciudadanos para no acudir a las urnas, se encuentran el escaso conocimiento de la UE, la falta de información y el poco interés en las elecciones al PE, en particular, y en asuntos europeos en general. Añade que "la escasa cobertura de los asuntos europeos y de las elecciones al PE en los medios de los Estados miembros, y el hecho de que la organización de la cita electoral, el contenido de sus
} 
acercamiento del PE a los parlamentos nacionales en cuanto a las funciones se refiere. Sin embargo, también es claro que habrá que estar vigilantes para asegurar bien los elementos de control democrático, con la finalidad de evitar la tendencia de todo poder a escaparse del control, que -según está bien asentado desde Montesquieu- sólo podrán ejercer realmente otros poderes; sobre todo cuando estamos hablando de un suprapoder que podría escaparse, aunque fuera sólo parcialmente, a los mecanismos de control. Deberá evitarse, por tanto, haciendo también aquí un paralelismo con los sistemas nacionales, la posible pérdida de primacía del Parlamento frente al poder ejecutivo, materializado primordialmente en la UE a través del Consejo Europeo (o incluso también frente al otro poder legislativo, personificado en el Consejo).

Lo cierto es que, como certeramente pone de relieve Araceli Mangas, la actuación del PE está siendo en la práctica considerablemente más democrática que la de algunos parlamentos nacionales, y en concreto también que la del español. Así, ofrece varios ejemplos muy gráficos de las diferencias existentes entre Bruselas (y Estrasburgo) y, por ejemplo, Madrid: la sujeción de los miembros de la Comisión al control previo del PE; la devolución de proyectos normativos por parte del PE; o la inexistencia de un mandato imperativo en el $\mathrm{PE}^{17}$. La verdad es que por estar constituidos los grupos parlamentarios europeos como tales, y no como grupos nacionales, se garantiza una mayor independencia en su actuación. Sin embargo, nada parecido ocurre en Parlamentos como el español, ya que, sin ir más lejos, pese a que existe una prohibición constitucional del mandato imperativo, existe una sujeción real de los diputados nacionales a él.

\footnotetext{
debates e incluso la elección de los candidatos se desarrollen en clave nacional, convierten la cita electoral en un trámite poco atractivo que, en muchas ocasiones, sirve para poco más que respaldar o castigar al gobierno de turno. La dificultad para identificar el impacto de su voto en la dirección de la UE y el efecto de las decisiones europeas en sus vidas contribuyen al desinterés ciudadano". Esta autora termina aventurando que tal vez en la convocatoria de 2014 se resienta todavía más la participación o que incluso sean "candidaturas antisistema las únicas capaces de movilizar a los ciudadanos descontentos con la Unión como consecuencia de su gestión de la crisis económica" y concluye que "una mayor voluntad de los gobiernos y de las instituciones europeas para mejorar el conocimiento de los ciudadanos en asuntos europeos, junto con una mayor determinación de los partidos políticos europeos por vertebrar mejor sus programas políticos siguiendo pautas más ideológicas, podrían ayudar también a despertar el interés ciudadano en la convocatoria electoral"; S. Piedrafita, "Los ciudadanos ante las elecciones europeas. Retos actuales y propuestas de reforma”, Panorama social, Núm. 17, 2013, pp. 148; p. 146.
} 


\section{Retos de la UE en la actual situación de crisis}

Aun reconociendo los avances producidos en el ámbito de la UE, es preciso, a nuestro juicio, avanzar más a fin de cumplir plenamente con el concepto de democracia, el cual se extiende a todas sus posibles facetas e implicaciones. Por consiguiente, concebimos la democracia no en un sentido minimalista, sino en su sentido integral, que no implica meramente un procedimiento de elección de los parlamentarios, sino una concepción cimentada en una amplia participación política, además de otros requisitos significativos como el del sometimiento de las instituciones al imperio de la ley, el principio de legalidad, la transparencia de la actuación pública y la vigencia del principio de la división de poderes en su más amplio sentido, es decir, velando por la existencia de mecanismos de control institucionales, que siempre han de ser de verdad independientes y puedan contrarrestar cualquier desviación de la legalidad de las diversas actuaciones públicas. Como se prevé en el propio Derecho de la Unión, cada institución deberá actuar dentro de los límites de las atribuciones que le confieren los Tratados constitutivos, con arreglo a los procedimientos, condiciones y fines establecidos en los mismos, manteniendo entre sí una cooperación leal (art 13.2 TUE).

Junto a este sometimiento al Derecho se hace imprescindible, para poder reconocer la existencia de una UE plenamente democrática, según nuestro criterio, cierta rectificación que permitiera seguir manteniendo los elementos cardinales del Estado social en vez de retroceder al respecto. Cabe plantearse aquí la siguiente interrogante: ¿Hasta qué punto se puede considerar que una sociedad con importantes sectores excluidos de la vida económica, profesional, cultural... es enteramente democrática? El modelo social que se fue forjando desde la II GM no debería ser desmantelado, máxime cuando todo el proceso de integración europea, desde sus inicios, colaboró activamente en su fortalecimiento, y cuando la Unión sigue postulando, en el art. 2 del TUE, que los valores compartidos por los Estados y sus pueblos suponen el "respeto de la dignidad humana, libertad, democracia, igualdad, Estado de Derecho y respeto de los derechos humanos, incluidos los derechos de las personas pertenecientes a minorías", y que estos valores reflejan una "sociedad caracterizada por el pluralismo, la no discriminación, la tolerancia, la justicia, la solidaridad y la igualdad entre mujeres y hombres". Sin embargo, no se puede negar que ahora mismo existe un distanciamiento real con respecto a estos valores, que sufren millones de ciudadanos. Precisamente por ello hay que ser también conscientes

A. Mangas Martín, "Listas responsables para Europa”, El Mundo, 02/03/2014, 
de que ese alejamiento coadyuva a su vez a agravar la distancia que muchos ciudadanos europeos sienten con respecto a sus instituciones.

De hecho, ciertas medidas adoptadas por la UE para intentar acabar con la crisis han sido sólidamente criticadas $^{18}$. Como es sabido, la crisis económica ha tenido más impacto en algunos países de la UE porque la unión monetaria se había echado a andar antes que la unión económica, con deficiencias básicas en su diseño. Para paliar estos problemas, la UE ha arbitrado cuatro principales frentes de actuación: mecanismos de emergencia, entre los que se encuentran los rescates y los mecanismos previstos para afrontarlos, medidas de gobernanza económica y fiscal, medidas hacia una unión bancaria y, por último, una estrategia de crecimiento. Pero en este contexto, la UE ha revelado tener diferentes posturas e intereses entre sus Estados miembros. Y, además, la estrategia de crecimiento adoptada hasta ahora no ha sido lo suficientemente fuerte para dar frutos. Se trata de problemas que, por un lado, amenazan el progreso de la UE como actor político y económico, y, por otro lado, también dificultan el desarrollo económico y el bienestar social de algunos de sus Estados miembros (a la vez que de ciertos sectores de población), entre ellos, el de España. Es preciso, por tanto, que este modelo de gobernanza económica supere esas deficiencias, a la vez que gane un mayor equilibrio entre crecimiento y austeridad, hasta ahora inexistente por poner demasiado peso en este segundo lado de la balanza. Parece necesario, en fin, reconducir el rumbo para que la siguiente etapa del proceso de integración europea se asiente sobre fundamentos firmes en estos ámbitos, y siempre considerando las necesidades de todos los Estados miembros.

Son desafíos que por supuesto no se ciñen al ámbito económico, y que se conectan con los valores de justicia social indicados más arriba, y en definitiva también con el desarrollo humano. En esta línea, habría una serie de objetivos que deberían ser irrenunciables para la $U^{19}{ }^{19}$, relacionados con medidas efectivas para hacer frente a algunos excesos de los mercados y la globalización; fomentar la independencia de las instituciones frente al poder económico y financiero; medidas eficaces para el favorecimiento real de la I+D+i; una estrategia coherente a fin de reducir el desempleo

\footnotetext{
disponible en http://www.elmundo.es/opinion/2014/03/02/53137485268e3eec068b4570.html.

${ }^{18}$ Véanse las contribuciones de varios autores en Gobernanza y Reforma internacional tras las crisis financiera y económica: el papel de la Unión Europea, La Reforma de las Instituciones Económicas Internacionales (Tomo II), C. Fernández Liesa y M. Abad Castelos (Directores) y J. Tuñón Navarro (Coordinador), Marcial Pons, Madrid, 2014 (en prensa).

${ }^{19}$ En este sentido, el antiguo director general de la UNESCO, Federico Mayor Zaragoza, cita en su blog un listado de objetivos a perseguir, localizables en http://federicomayor.blogspot.com.es.
} 
y en favor del empleo no precario ${ }^{20}$; la persecución de la evasión fiscal y por ende de los paraísos fiscales; mantener su alto nivel de compromiso en materia de protección medioambiental y de lucha contra el cambio climático, etc.

Hay que partir, en definitiva, de que "es dudosa la existencia de un auténtico espacio público europeo", lo cual exige todavía nuevos esfuerzos ${ }^{21}$. Pero "en este contexto de crisis, y a pesar de las presiones por dar respuestas inmediatas, como decía a finales de 2012 quien en el momento de redactar estas páginas era aún el presidente del Parlamento europeo, Martin Shulz, tenemos la responsabilidad de evitar la desparlamentarización de la gobernanza económica en Europa”, siendo necesario trabajar codo con codo con los Parlamentos nacionales para "reforzar los mecanismos de coordinación parlamentaria y contrarrestar así esta peligrosa tendencia" ${ }^{22}$, a la vez que se gana en legitimidad y se compensa la erosión de la posición de la $\mathrm{UE}^{23}$.

\section{Conclusión: la importancia del PE y de las elecciones europeas}

Nos gustaría concluir reconociendo los importantes progresos que la UE ha conseguido, pero siendo también conscientes de algunos de sus problemas y

\footnotetext{
${ }^{20}$ Para una fundada crítica con respecto a la ordenación de las relaciones laborales en la UE, véase el comentario de M. Correa Carrasco, "El Programa Europeo para el Empleo y la Innovación Social (“EaSI"): ¿un nuevo paso en la lucha contra el desempleo en Europa?", en Revista General de Derecho Europeo, núm. 33, 2014. El autor concluye afirmando que la situación "presenta graves deficiencias que se deben, principalmente, a los escasos avances que se han producido en la integración y convergencia de las respectivas legislaciones nacionales, al estar la competencia jurídica en la materia en manos de los Estados. Ello reduce notablemente la operatividad de las políticas de empleo que, a la postre, devienen ineficaces para afrontar un problema que, agravado por la crisis económica, se deriva esencialmente del modelo de relaciones laborales resultante de la globalización económica y la competencia de las economías emergentes. De ahí que, frente a este reto, sean claramente insuficientes las referencias del Programa al compromiso asumido por la UE de 'reforzar la dimensión social de la globalización y luchar contra el dumping social mediante la promoción de un trabajo digno', si ello no se traduce en el propósito decidido de establecer una reglamentación uniforme que se concrete en una serie de medidas, de diversa índole (sociales, económicas, financieras) y amplio espectro, que supongan un claro avance hacia la integración política y que, en última instancia, tengan la virtualidad de construir un verdadero modelo europeo de relaciones laborales con capacidad de proyectarse a escala internacional".

${ }^{21}$ N. Levrat, La construction européenne est-elle démocratique?, La Documentation française, Paris, 2012, pp. 86 y ss. G. Garzón suscribía en 2012 esta idea y citaba específicamente la necesidad de reformar el Acta electoral europea y de los partidos políticos a escala europea; G. Garzón Clariana, "Introducción”, Ciudadanía europea y Democracia... op. cit., p. 23.

${ }^{22}$ M. Shulz, "Prefacio", Ciudadanía europea y Democracia... op. cit., pp. 15-17; p. 17.

${ }^{23}$ A este último respecto, véase O. Cramme, A. Meyer y J. Ritzen, "A New Promise for Europe. How the elections to the European Parliament can stop Eurosion", Policy Network Paper, September 2013 (www.policy-network.net).
} 
desafíos en estos momentos actuales de encrucijada, de transición, e incluso de posible cambio de paradigma en las políticas estatales. La UE ha hecho mucho, pero queda todavía mucho por hacer. Y lo que queda, se puede hacer de diversas maneras... En todo caso, la UE debe continuar consolidando los elementos que garantizan unas instituciones totalmente sometidas al Derecho, y con unos derechos de participación política que puedan calificarse de predeterminados, inalienables y ejemplares. $Y$ esto ya es también tarea de todos los europeos. Baste con acabar recordando la importancia del PE y del propio Presidente de la Comisión, que será elegido por el primero y tendrá influencia, dentro de los países de su esfera, en los diversos ámbitos de la política, la economía y de las propias vidas de sus ciudadanos. Por ello, el conjunto de la ciudadanía europea habrá de ser muy consciente de que las elecciones europeas no pueden ser consideradas como unas elecciones de segunda categoría, porque ya no lo son. Deberá, en consecuencia, saber otorgarle la importancia que realmente tienen, puesto que a través de ellas se puede influir decisivamente en el futuro de los 28 países de la Unión Europea. 


\section{Referencias bibliográficas}

BECK, U. "La sociedad del riesgo (hacia una nueva modernidad)" Traducción de J. Navarro, D. Jiménez y M.R. Borrás), 1a Edición en castellano, Paidós, Barcelona, 1998.

COMISIÓN EUROPEA, IP/13/725 23/07/2013 (disponible en http://europa.eu/rapid/press-release_IP-13-725_es.htm).

CORREA CARRASCO, M., "El Programa Europeo para el Empleo y la Innovación Social (“EaSI"): ¿un nuevo paso en la lucha contra el desempleo en Europa?", en Revista General de Derecho Europeo, núm. 33, 2014.

CRAMME, O., MEYER, A. y RITZEN, J., "A New Promise for Europe. How the elections to the European Parliament can stop Eurosion", Policy Network Paper, September 2013 (www.policy-network.net).

ESTEBAN, M., "El ascenso de China y Asia: ¿qué nos dice el Índice Elcano de Presencia Global?", $A R I, 14 / 2014$ - 6/3/2014.

\section{European Citizen Action Service:}

"European Citizens' Initiatives - A first assessment", Background Discussion Document No. 1 for the Conference "Building the EU Citizen pillar", November 2012 (European Economic and Social Committee), Brussels, Belgium (http://www.ecascitizens.eu/content/view/468/).

Bringing transnational participatory democracy to life: tips for the would-be organisers of an ECI, July. ECAS publication, Brussels, Belgium, 2011.

FERNANDEZ LIESA, C. y ABAD CASTELOS, M. (Directores) y TUÑÓN NAVARRO, J. (Coordinador) (2014) "Gobernanza y Reforma internacional tras las crisis financiera y económica: el papel de la Unión Europea, La Reforma de las Instituciones Económicas Internacionales" (Tomo II), Marcial Pons, Madrid, (en prensa).

GARZÓN CLARIANA, G. (2012) "Introducción”, Ciudadanía europea y Democracia. La reforma del acta electoral y de los partidos políticos europeos, G. Garzón Clariana (Ed.), Marcial Pons, Madrid, pp. 23 y ss.

KAUFFMANN, B. (2012) "European Citizens' Initiative Pocket Guide", Initiative and Referendum Institute and the Green Foundation, March 2012, Belgium.

LEVRAT, N. (2012) La construction européenne est-elle démocratique?, La Documentation française, Paris, pp. 86 y ss.

LIÑÁN NOGUERAS, D. y MANGAS MARTIN, A. (2012), Instituciones y Derecho de la UE, Tecnos, Madrid.

MANGAS MARTIN, A., "Listas responsables para Europa”, El Mundo, 02/03/2014, disponible en

http://www.elmundo.es/opinion/2014/03/02/53137485268e3eec068b4570.html. 
MARTÍN DE HIJAS MERINO (2010) "Sistema electoral al Parlamento Europeo", Estado Democrático y Elecciones Libres: Cuestiones fundamentales de Derecho electoral, Thomson Reuters, pp. 321-361.

MAYOR ZARAGOZA, F. Blog. URL: http://federicomayor.blogspot.com.es.

MÉNDEZ DE VIGO, I. (2012) "Prólogo", Ciudadanía europea y Democracia. La reforma del acta electoral y de los partidos políticos europeos, G. Garzón Clariana (Ed.), Marcial Pons, Madrid, pp. 19-22.

MORAVCSIK, A. (2002) "In Defence of the Democratic Deficit: Reassessing Legitimacy in the European Union", Journal of Common Market Studies, Vol. 40, pp. 603-624.

PIEDRAFITA, S. (2013) "Los ciudadanos ante las elecciones europeas. Retos actuales y propuestas de reforma", Panorama social, Núm. 17, pp. 148; p. 146.

RODRÍGUEZ JIMÉNEZ, J.L. (2004) La extrema derecha europea, Alianza Editorial, Madrid 2004. RODRÍGUEZ JIMÉNEZ, J.L "Como rentabilizar los sentimientos xenófobos" (2005), Crítica, Núm. 925, pp. 36 y ss.

RODRÍGUEZ, IGLESIAS, G.C. y LÓPEZ ESCUDERO, M. (2010) "Estructura institucional de la Unión Europea", Las Organizaciones Internacionales, M. Díez de Velasco (16 edición, coordinada por J.M. Sobrino Heredia), Tecnos, Madrid, 2010, pp. 617 y ss.

RODRÍGUEZ- AGUILERA DE PRAT, C. (2012) "Euroescepticismo y partidos radicales: ¿todos iguales?", Ciudadanía europea y Democracia. La reforma del acta electoral y de los partidos políticos europeos, G. Garzón Clariana (Ed.), Marcial Pons, Madrid, pp. 143-156.

SCHULZ, M. (2012) "Introducción", Ciudadanía europea y Democracia. La reforma del acta electoral y de los partidos políticos europeos, G. Garzón Clariana (Ed.), Marcial Pons, Madrid, pp. 23-27.

TORREBLANCA, J.I. (2013) “Unión Europea: del 'superávit democrático' al 'déficit democrático', en J. Estefanía, Informe sobre la Democracia en España, Fundación Alternativas, Madrid. 